\title{
PREDICTION OF ADIABATIC FILM COOLING EFFECTIVENESS OVER FLAT PLATE WITH CYLINDRICAL AND SHAPED FILM
}

\section{HOLES}

\author{
Dhulesh Mirje ${ }^{1}$, Batchu Suresh ${ }^{2}$, HRPurushothama ${ }^{3}$ \\ ${ }^{1}$ M.Tech student, SIT Tumakuru \\ ${ }^{2}$ Scientist ' $F$ ', HTG, GTRE, DRDO \\ ${ }^{3}$ Associate Professor, Mechanical Engineering Department, SIT, Tumakuru \\ Email: ${ }^{3}$ dhuleshmirje123@gmail.com, ${ }^{2}$ batchusuresh71@gmail.com, ${ }^{3}$ hrp_sit@yahoo.co.in \\ Contact Number: ${ }^{1}+\mathbf{9 1 - 9 7 4 2 4 3 9 7 7 4}$
}

\begin{abstract}
Increasing the creep life of gas turbine blades can be achieved by cooling the blades effectively. Film cooling is an effective method of cooling the blade surface. To improve the cooling effectiveness, recent attention has been given to contour the film hole shape. Film cooling holes with diffuser-shaped and expanded exits will improve the film-cooling performance on a gas turbine blade. The present study aims at estimating the adiabatic film cooling effectiveness downstream of cylindrical and laid back fan shaped holes on a flat plate using Fluent CFD software. Analysis is carried out to identify the suitable turbulence model for predicting the film cooling effectiveness on a flat plate. The effect of blowing ratio and turbulence intensity on film cooling effectiveness is brought out in this study. The advantage of adopting laidback fan shaped film hole over cylindrical film hole is highlighted.
\end{abstract}

Keywords: Film Cooling Effectiveness, Blowing Ratio, Cylindrical Hole Model (CHM), Laidback Fan Shaped Hole Model (LBFSHM)

\section{INTRODUCTION}

Flat plate models with different film cooling hole shapes are used to analyse the distribution of film cooling effectiveness over the flat plate surface.Film cooling is a major turbine blade cooling method. The optimization of turbine blade film cooling requires the investigation of various geometrical and flow parameters like cooling hole shape, hole location, diameter of the hole, hole angle with respect to blade surface, coolant to mainstream blowing ratio (B.R) and density ratio (D.R). Amongst them, blowing ratio has significant effect on the film cooling effectiveness.

Giridhara etal.[1] experimentally studied that film cooling effectiveness is directly proportional to hole orientation angle with highest value observed for $45 \mathrm{deg}$. angle model and numerically evaluated that $\mathrm{k}-\varepsilon$ turbulence model show values nearer to the experimental values. M.Gritsch et al.[2] showedthat holes with expanded exits show significantly improved film cooling effectiveness particularly at high blowing ratios and laid back fan shaped hole provides better laterally averaged effectiveness because of better lateral spreading.

J.Felix et al.[3] showed that effectiveness value is higher immediately downstream of the film hole and decreases as $\mathrm{X} / \mathrm{D}$ increases. Also it is found that adiabatic film cooling effectiveness is higher for model with higher area ratio than the lower area ratio. Giridhara babu et al.[4] studied the experimental investigation of adiabatic film cooling effectiveness over a Circular, Fan and Laid back fan shaped hole flat plate test models and found that the Laid back fan shaped hole model shows the higher film cooling effectiveness than the Circular and Fan shaped holes model at all the Blowing ratios ranging from 0.5 to 2.5 . Ronald.S.Bunker[5] studied the variation of film cooling effectiveness over shaped holes for different blowing ratios and found that film cooling effectiveness is very less sensitive to change in turbulent intensity. N.Vinod kumar et al. [6] experimentally evaluated film cooling effectiveness and observed that the extended triangular shaped holes give better film coverage over flat surface than triangular and cylindrical shaped holes. Ibrahim M Hasan et al. [7] studied the effect of forward and lateral diffusion angle of the film cooling hole on effectiveness varying it from $0^{0}$ to $15^{0}$. They found that with increase in blowing ratio, sensitivity of effectiveness to shaped hole diffusion angles increases and is maximum at blowing ratio of 2.5 .

\section{PROBLEM DESCRIPTION}

The aim of the present work is to study the computational fluid dynamics (CFD) analysis of adiabatic film cooling on flat plate model with cylindrical and laidback fan shaped holes. 


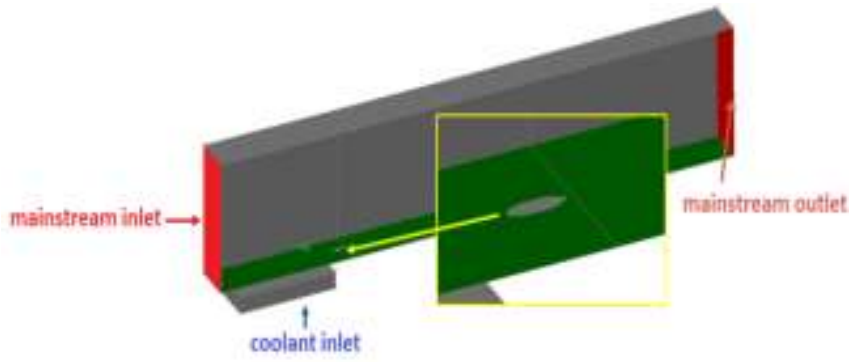

Figure 1: Typical flat plate model

The CFD analysis is performed for different coolant to mainstream mass flux ratios (Blowing ratio) ranging from 0.5 to 2.5 with a step of 0.5 . CFD analysis for determining suitable turbulence model is carried and finally effect of the blowing ratio, and turbulent intensity on film cooling effectiveness is studied. A typical shaped hole flat plate model is shown in Figure 1.

\section{MODEL CONFIGURATION}

The present study is carried out for a flat plate model with two rows of holes with symmetry boundary conditions maintained at the vertical pitch plane.

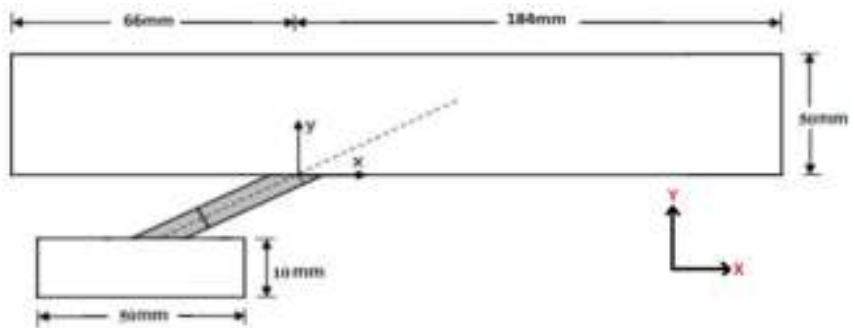

Figure 2: geometry of mainstream and coolant domains (2D)

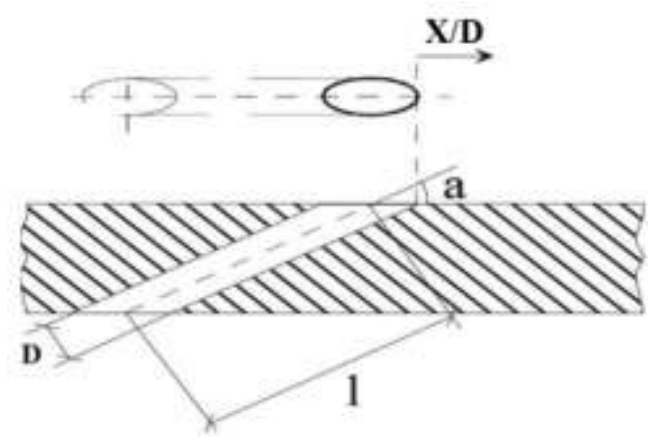

Figure 3: Cylindrical hole geometry
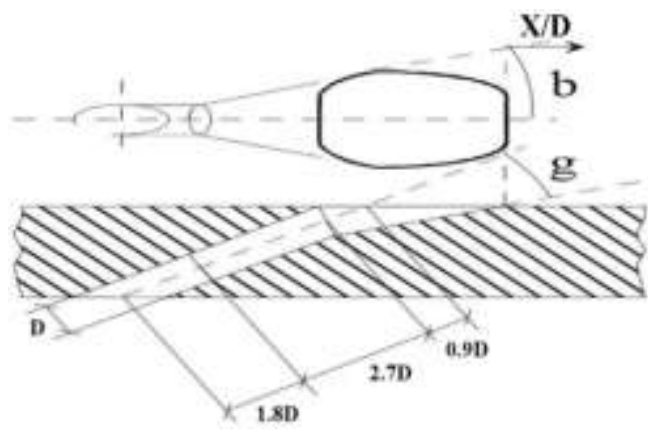

Figure 4: Laidback fan shaped hole geometry
Figure 2 represents the 2D geometric configuration of mainstream and coolant domains.Both the mainstream gas side and coolant side are modelled as rectangular ducts. The coolant chamber is made at the bottom to pass the coolant which then mixes with mainstream hot gas to form a coolant film over the bottom wall surface.

Figure 3 and Figure 4 show the geometric representations of cylindrical hole model and laidback fan shaped hole model respectively. The diameter of the cooling hole is ' $\mathrm{D}$ ' $\mathrm{mm}$, its length is ' $\mathrm{l}$ ' $\mathrm{mm}$ and stream wise injection angle is kept at ' $\mathrm{a}$ ' degree. A hole to hole pitch of ' $\mathrm{P}$ ' $\mathrm{mm}$ (span wise pitch) and row to row pitch of ' $\mathrm{P} 1$ ' $\mathrm{mm}$ (stream wise pitch) is maintained between the holes.

In case of laidback fan shaped hole ' $b$ ' and ' $g$ ' represent the lateral and forward diffusion angles respectively. Also the circular length, fan shape length and laidback fan shape length are taken as $1.8 \mathrm{D}, 2.7 \mathrm{D}$ and $0.9 \mathrm{D}$ respectively.

\section{COMPUTATIONAL GRID GENERATION}

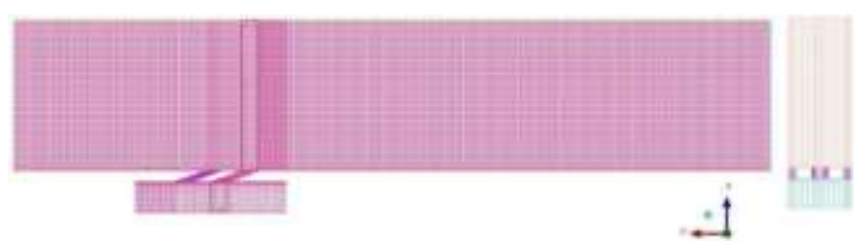

Figure 5: Computational Grid

Multi block hexahedral grid approach is used for the present study because it allows highest quality in all regions. ICEM 14.0 meshing tool is used for creating the mesh. Hexahedrons grid is used as they provide more accurate solutions for flows near boundary layers. Fine grid near the surface is maintained which results in better average y+ values. The mesh generated for model under current study is shown in Figure 5.

\section{BOUNDARY CONDITIONS}

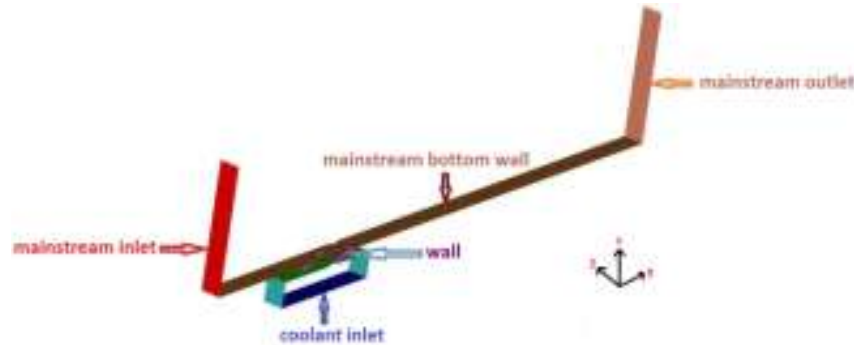

Figure 6: Nomenclature of boundary conditions applied on flat plate model

Figure 6 represents the nomenclature of boundary conditions applied on the model under current study. Inlet pressures and inlet temperatures of mainstream gas side and coolant side are applied to carry the CFD analyses. 
Table 1: Boundary conditions applied at Blowing Ratio of 2.5

\begin{tabular}{|c|c|c|}
\hline & $\begin{array}{c}\text { Cold stream } \\
\text { side }\end{array}$ & $\begin{array}{c}\text { Mainstream } \\
\text { side }\end{array}$ \\
\hline Inlet pressure (gauge) & $748 \mathrm{~Pa}$ & $225 \mathrm{~Pa}$ \\
\hline Temperature & $223 \mathrm{~K}$ & $363 \mathrm{~K}$ \\
\hline Operating pressure & \multicolumn{2}{|c|}{$91998 \mathrm{~Pa}$} \\
\hline
\end{tabular}

Table 1 represents the boundary conditions applied to perform the CFD analysis at blowing ratio of 2.5. The analysis is carried out for different blowing ratios, maintained by varying the coolant pressure, with the main stream mass pressure kept at a constant value.

\section{Adiabatic Film Cooling Effectiveness Measurement}

The adiabatic film cooling effectiveness $(\eta)$ is measured using the following relation:

$\eta=(\mathrm{Tms}-\mathrm{Tw}) /(\mathrm{Tms}-\mathrm{Tc})$

Where, Tms = Main stream temperature

$\mathrm{Tw}=$ Local Wall temperature

Tc $=$ Coolant temperature

\section{RESULTS AND DISCUSSION}

Selection of suitable turbulence model

CFD study is carried out over cylindrical and shaped hole model at blowing ratio of 1.5 to determine the suitable turbulence model that can produce results nearer to the experimental results [4]. Realizable $\mathrm{k}-\varepsilon$ turbulence model with enhanced wall functions and $\mathrm{k}-\omega$ SST turbulence model are considered for this CFD analysis.

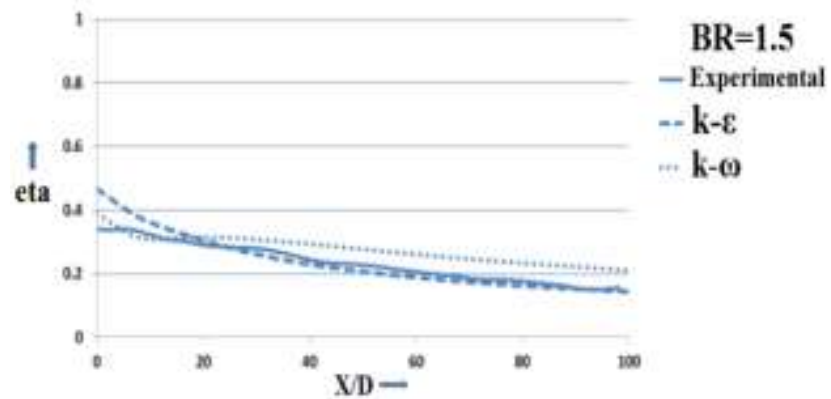

Figure 7: Comparison of experimental and CFD film effectiveness over cylindrical hole model

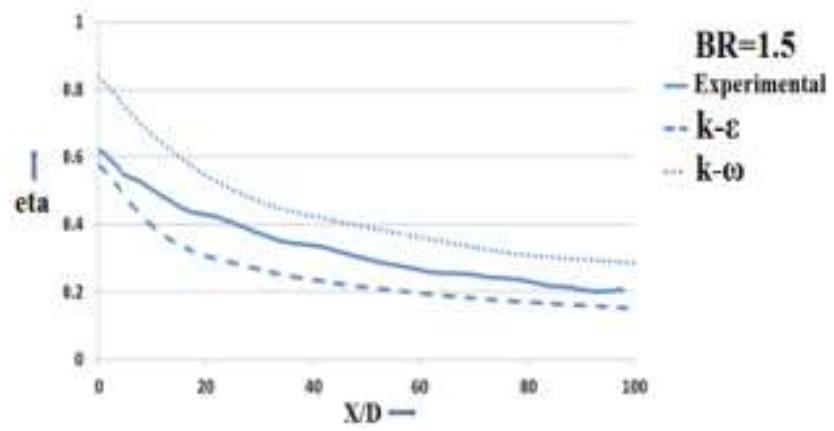

Figure 8: Comparison of experimental and CFD film effectiveness over laidback fan shaped hole model
Figure 7 and Figure 8 show the comparison of laterally averaged effectiveness between experimental data, CFD data withk- $\varepsilon$ model and CFD data with $\mathrm{k}-\omega$ model for cylindrical and laidback fan shaped hole models respectively. The analyses are carried out at blowing ratio of 1.5 with effectiveness measured along the downstream starting from the immediate downstream of second row of holes.

It is clear from both the figures that the results ofCFD study with $\mathrm{k}-\varepsilon$ turbulence model predicts closer to the experimental data [4]. Hence $\mathrm{k}-\varepsilon$ turbulence model is preferred for all the following effectiveness studies.

Film cooling analysis on flat plate model with cylindrical holes

The CFD study of film cooling over cylindrical hole flat plate model is performed using $\mathrm{k}-\varepsilon$ turbulence model at different blowing ratios ranging from 0.5 to 2.5 with a step of 0.5.Non-dimensional total temperature contoursover the mainstream bottom wallat different blowing ratios are shown in Figure 9.

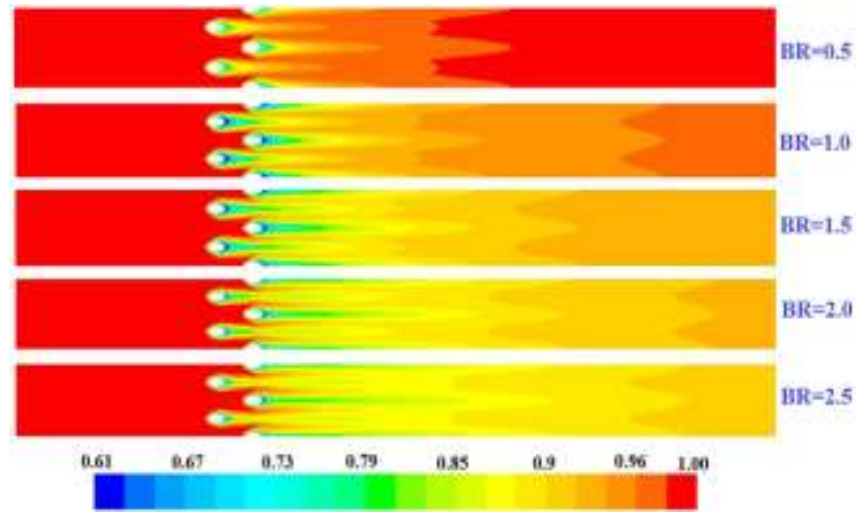

Figure 9:Non-dimensional total temperature contours over the mainstream bottom wall of cylindrical hole flat plate model

From figure 9it is noticed that the coverage of film over the surface increases with increase in blowing ratio (BR) due to the increase in coolant mass flow. For a particular blowing ratio, effectiveness is higher near the downstream of the hole due to the coolant film formation and it goes on decreasing along the downstream direction.

Non-dimensional totaltemperature contoursoverX-Y plane of cylindrical hole model andY-Z planecut at $1 \mathrm{~mm}$ downstream of second row of holes perpendicular to the mainstream flow are shown in Figure 10 and Figure 11 respectively. 


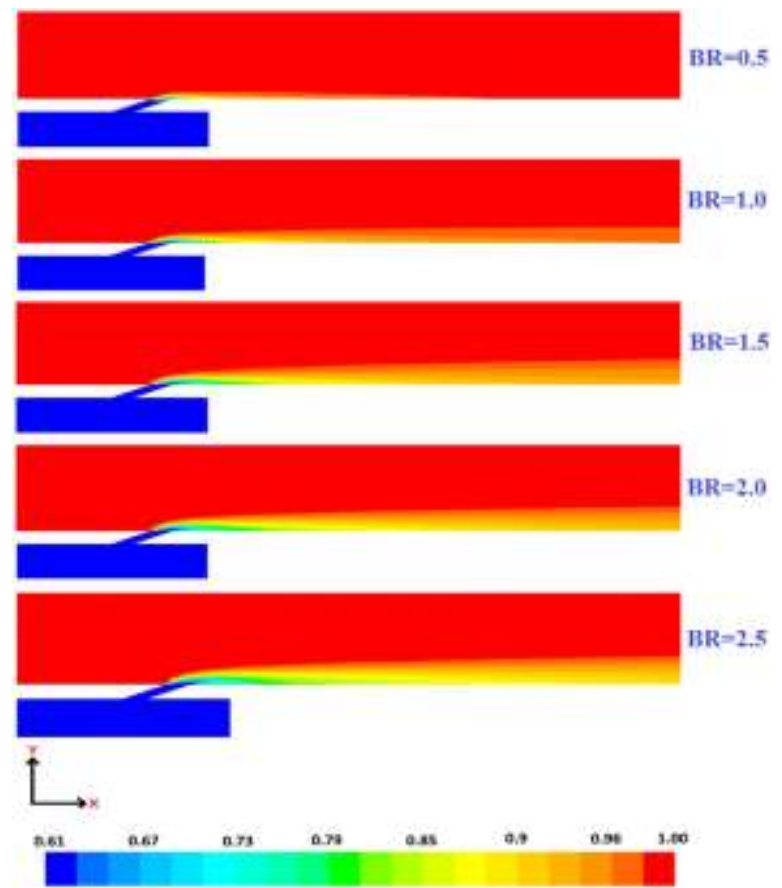

Figure 10:Non-dimensional total temperature contours over $\mathrm{X}-\mathrm{Y}$ plane
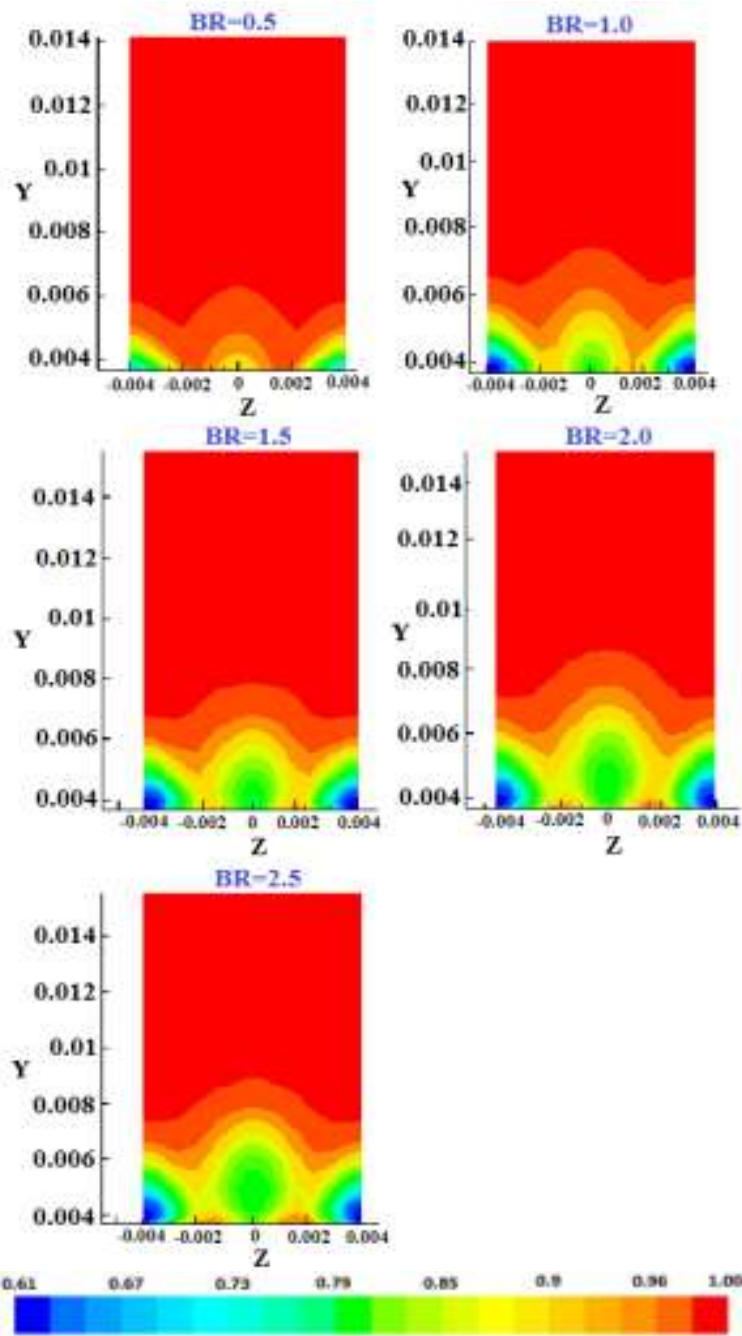

Figure 11: Non-dimensional total temperature contours over Y-Z plane

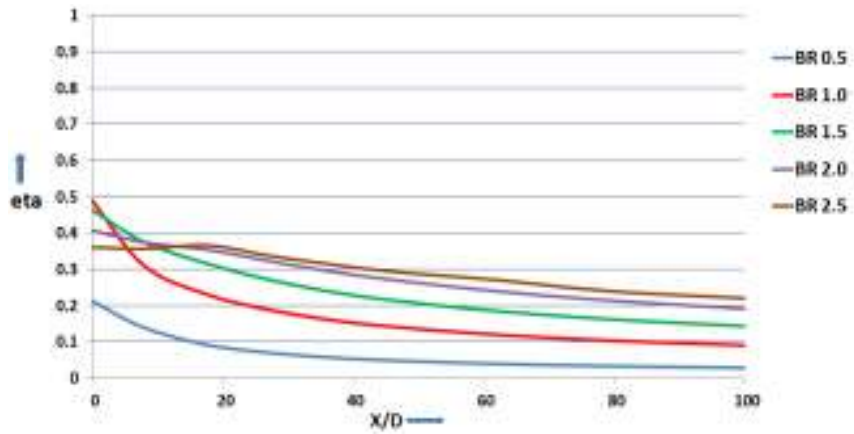

Figure 12:Laterally averaged film cooling effectiveness along the downstream of cylindrical holesat different blowing ratios

Figure 12 shows the effect of blowing ratio on adiabatic film cooling effectiveness for cylindrical hole model. The effectiveness values are measured along the downstream with initial value taken from immediate downstream of the second row holes.It is seen that effectiveness increases with increase in blowing ratio. At higher blowing ratios, increase in coolant jet momentum causes penetration of coolant into mainstream flow and results in coolant jet lift-off. This phenomenon can be observed in Figure10 and Figure11.Therefore a decrease in film effectiveness is observed at the region immediately after the second row of holes from blowing ratio of 1.5.The highest effectiveness of 0.49 is observed for cylindrical hole model at blowing ratio of 1.0. Also there is no significant difference between effectiveness measured for blowing ratio of 2.0 and 2.5.

Film cooling analysis on flat plate model with laidback fan shaped holes

The film cooling analysis is carried out for laidback fan shaped hole flat plate model using $\mathrm{k}-\varepsilon$ turbulence model at different blowing ratios ranging from 0.5 to 2.5 with a step of 0.5.Non-dimensional total temperature contours over the mainstream bottom wall of laidback fan shaped hole flat plate model at different blowing ratios are shown in Figure13.

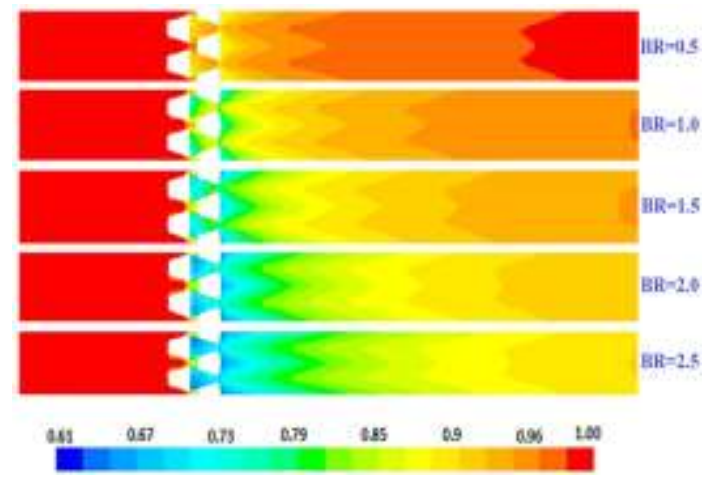

Figure 13: Non-dimensional total temperature contours over the mainstream bottom wall oflaidback fan shaped hole flat plate model

From Figure 13 it isobserved that the coverage of coolant film over the flat surface of shaped hole model is reasonably better as compared to cylindrical hole model at all the 
blowing ratios. This indicates that the laidback fan shaped holes provide better film coverage over the surfacecompared to cylindrical holes.
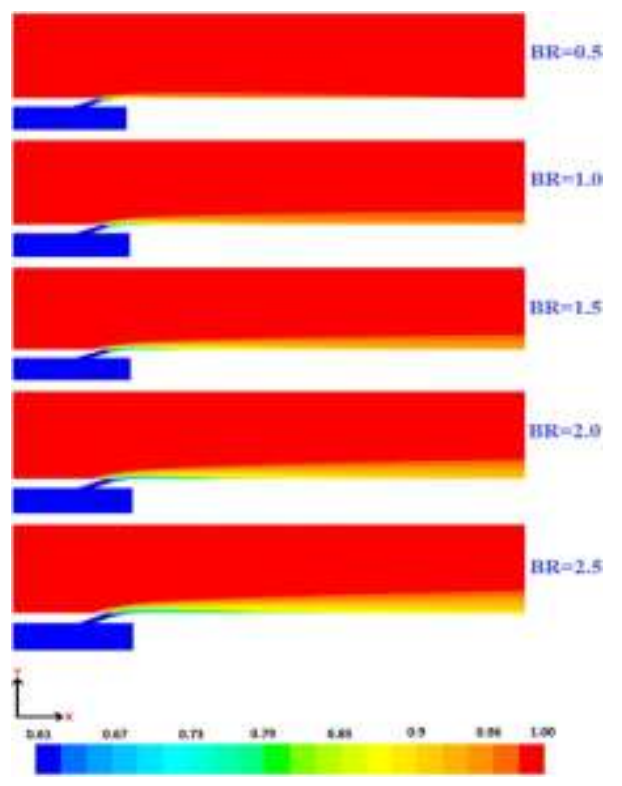

Figure 14: Non-dimensional total temperature contours over $\mathrm{X}-\mathrm{Y}$ plane

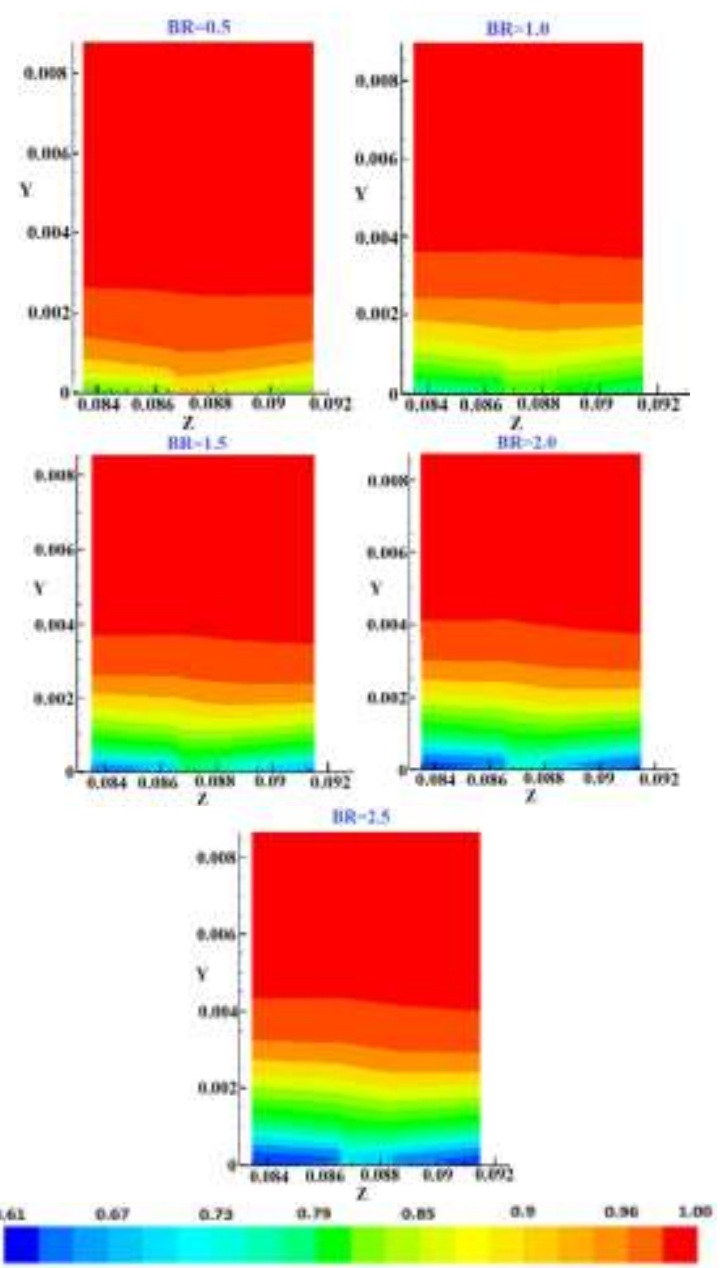

Figure 15: Non-dimensional temperature contours over $Y-Z$ plane
Non-dimensional total temperature contours over X-Y plane of laidback fan shaped hole model and Y-Z plane cut at $1 \mathrm{~mm}$ downstream of second row of holes perpendicular to the mainstream flow are shown in Figure 14 and Figure 15 respectively.

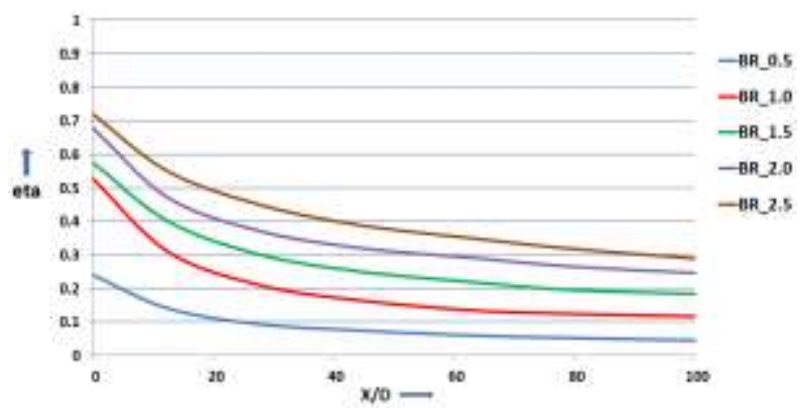

Figure 16:Laterally averaged film cooling effectiveness along the downstream of laidback fan shaped holes at different blowing ratios

From Figure 16it is observed that the film cooling effectiveness over the flat surface increases with increase in blowing ratio and the highest value of 0.71 is observed at blowing ratio of 2.5. In case of laidback fan shaped holes the lateral and forward diffusion of the hole prevent detachment of the coolant jet from the hole surface and helps in better lateral spreading of the film over the flat surface which can be noticed in Figure 14 and Figure 15. Therefore, with increase in blowing ratio unlike cylindrical holes there is no decrease in effectiveness observed at the region near the downstream of second row of holes.

Comparison of film cooling effectiveness between cylindricalhole (CHM) and laidback fan shaped hole (LBFSHM) flat plate models

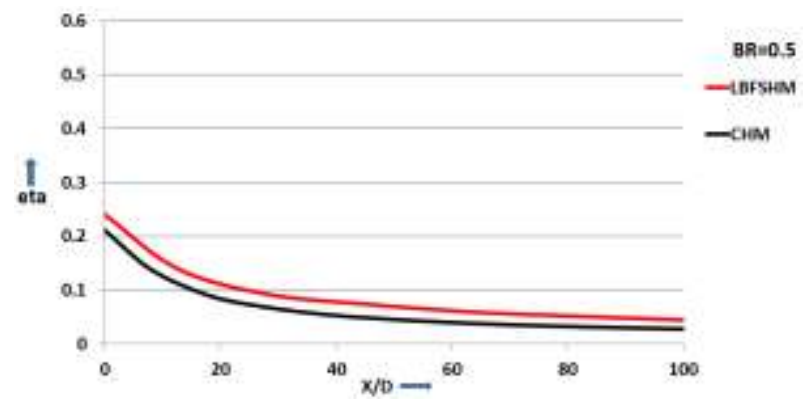

Figure 17: Laterally averaged film effectiveness along downstream direction at $\mathrm{BR}=0.5$

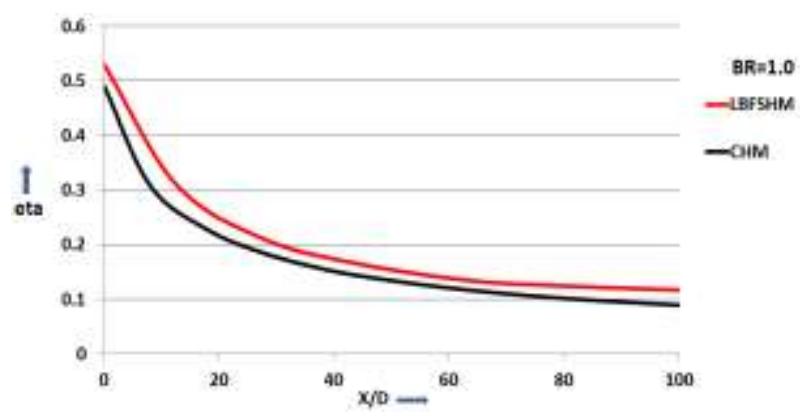

Figure 18: Laterally averaged film effectiveness along downstream direction at $\mathrm{BR}=1.0$ 


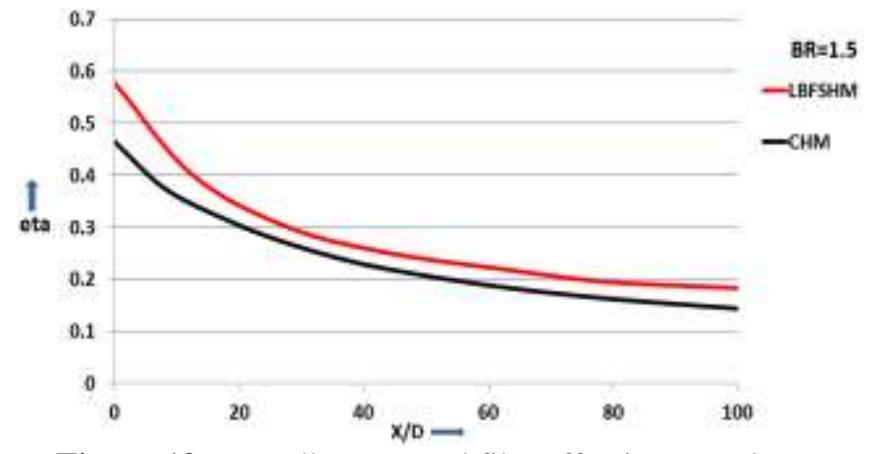

Figure 19:Laterally averaged film effectiveness along downstream direction at $\mathrm{BR}=1.5$

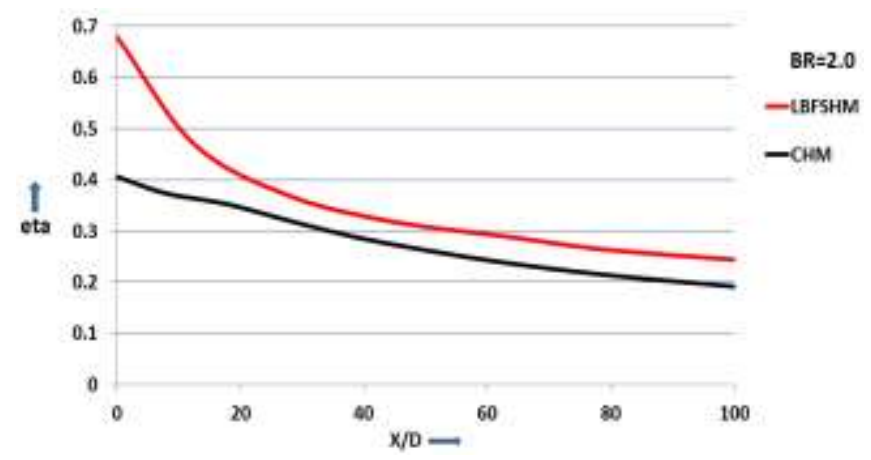

Figure 20:Laterally averaged film effectiveness along downstream direction at $\mathrm{BR}=2.0$

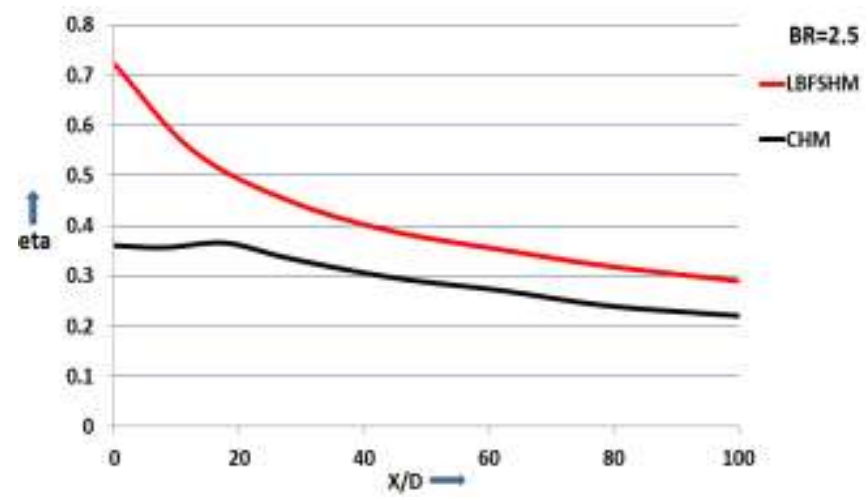

Figure 21:Laterally averaged film effectiveness along downstream direction at $\mathrm{BR}=2.5$

From Figure 17 to Figure 21 it is observed that film cooling effectiveness values are higher for laidback fan shaped hole compared to cylindrical hole for the blowing ratios ranging from 0.5 to 2.5 . However, much difference in effectiveness is observed between the two configurations up to X/D of 30.An overall percentage increment in effectiveness of $19 \%, 22 \%, 25 \%, 29 \%$ and $36 \%$ at blowing ratios $0.5,1.0,1.5,2.0$ and 2.5 respectively is observed for laidback fan shaped holes over cylindrical holes.

Effect of turbulent intensityon film cooling effectiveness

The CFD analyses are carried out over cylindrical and laidback fan shaped hole flat plate models at blowing ratios 1.0 and 2.0 by varying mainstream inlet turbulent intensityfrom $5 \%$ to $20 \%$ with a step of $5 \%$.

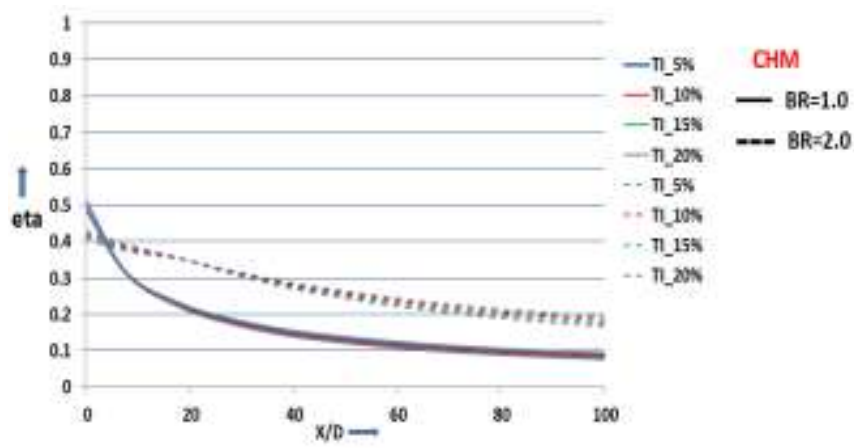

Figure 22:Laterally averaged film effectiveness along the downstream of cylindrical holes for different mainstream turbulent intensities

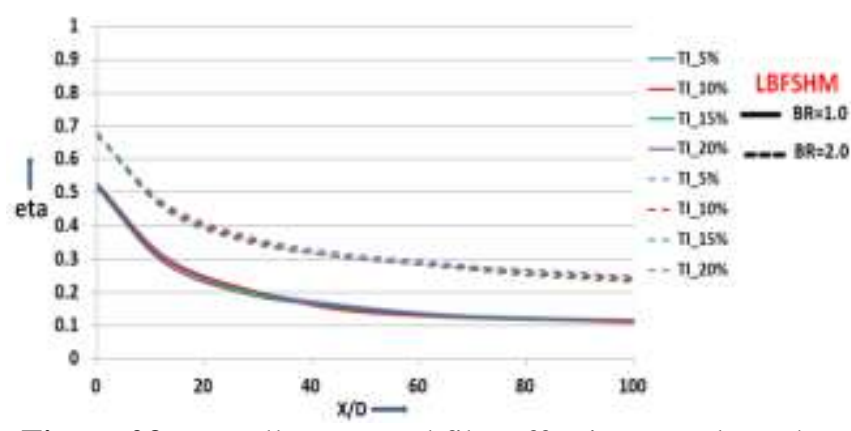

Figure 23:Laterally averaged film effectiveness along the downstream of laidback fan shaped holes for different mainstream turbulent intensities

Figure 22 and Figure 23 show that the variation in film cooling effectiveness values is negligible with the change in turbulent intensity. Thus, film cooling effectiveness is very less sensitive to the change in turbulent intensity.

\section{CONCLUSIONS}

CFD analysis is carried out for cylindrical and laid back fan shaped film hole over flat plate using $k-\varepsilon$ and $k-\omega$ turbulence models. The CFD analysis showedthat the film cooling effectiveness with $\mathrm{k}-\varepsilon$ turbulence model agreed well with the experimental data.

The numerically evaluated adiabatic film cooling effectiveness results show that the highest effectiveness values are observed near the hole downstream and goes on decreasing along the downstream direction. However, maximum difference in film cooling effectiveness is observed up to X/D of 20 in all the cases.Film cooling effectiveness increase with increase in blowing ratio for both cylindrical and laidback shaped configuration. Among the two considered models, the comparative results clearly show that the cooling effectiveness is higher for laidback fan shaped holes at all the cases of blowing ratios ranging from 0.5 to 2.5 . There is reasonable improvement in the cooling effectiveness from cylindrical hole to laid back fan shaped holes. Hence, the laidback fan shaped hole configurationproves beneficial for the implementation on the nozzle guide vane and rotor blades of turbineto attain higherfilm cooling performance. 
The analyses showed that the variation offilm cooling effectiveness is very lowwith the change in turbulent intensity from $5 \%$ to $20 \%$.

\section{ACKNOWLEDGEMENT}

The authors would like to thank Shri. M Z Siddique, Outstanding Scientist \& Director, Gas Turbine Research Establishment (GTRE) for permitting to publish the paper.

\section{REFERENCES}

[1]Giridhara Babu Yepuri, Felix Jesuraj, et.al., “ Experimental and Numerical investigation of effect of Blowing Ratio on Film Cooling effectiveness and Heat Transfer Coefficient over a gas turbine blade leading edge film cooling configurations", Proceedings of the ASME 2013 Gas Turbine India Conference, GTINDIA2013-3552

[2] M.Gritsch, A.Schulz, S.Witting, "Adiabatic wall effectiveness measurements of film-cooling holes with Expanded Exits", July 1998, Vol. 120/549

[3] J.Felix, Y.Girirdhara Babu, "Effect of film cooling hole area ratio on adiabatic film cooling effectiveness over a flat plate", Proceedings of the ASME 2013 Gas Turbine India Conference, GTINDIA 2013-3629

[4] Giridhara babu, Kesavan.V., et.al., "Experimental investigation of Adiabatic Film Cooling Effectiveness over a Circular, Fan and Laidback fan shaped hole flat plate test models, Proceedings of the ASME 2015 Gas Turbine India Conference, GTINDIA2015-1394

[5] Ronald.S.Bunker, "A review of shaped hole turbine film cooling technology”, April 2005, Vol. 127/441

[6] N.Vinod kumar et.al., "Effect of hole shape on film coolingeffectiveness over a flat plate"

[7] Ibrahim M Hasan et.al., " Numerical computations of gas turbine combustion products effects on film cooling effectiveness", Propulsion and Energy Forum, July 2830, 2014, Cleveland, $\mathrm{OH}$ 